\title{
Managing incidental genomic findings: legal obligations of clinicians
}

\author{
Ellen Wright Clayton, JD, MD ${ }^{1,2}$, Susanne Haga, $\mathrm{PhD}^{3}$, Patricia Kuszler, JD, MD ${ }^{4,5}$, Emily Bane, MPH${ }^{5}$, \\ Krysta Shutske, $\mathrm{MPH}^{5}$ and Wylie Burke, MD, $\mathrm{PhD}^{5,6}$
}

Purpose: Clinical whole-exome and whole-genome sequencing will result in a broad range of incidental findings, but clinicians' obligations to identify and disclose such findings are a matter of debate. We sought legal cases that could offer insights into clinicians' legal liability.

Methods: We searched for cases in which incidental findings were related to the cause of action, using the search engines WestLaw, WestLaw Next, Lexis, and Lexis Advance.

Results: We found no case law related to incidental findings from genetic testing but identified eight cases involving incidental findings in medical imaging. These cases suggest that clinicians may face liability for failing to disclose incidental findings that would have offered an opportunity for interventions to improve health outcome, if under the applicable standard of care, they fail to identify or appreciate the significance of the incidental finding or they negligently fail to notify other clinicians and/or the patient of the identified incidental finding. Other cases support liability for failure to refer appropriately to a clinician with greater expertise.

Conclusions: Clinicians may face liability if they fail to disclose incidental information that could inform interventions to improve health outcome; information lacking clinical actionability is likely to have less import.

Genet Med 2013:15(8):624-629

Key Words: genomics; incidental findings; medical malpractice; radiology

the research setting, ${ }^{5-9}$ consideration of these issues in the clinical setting is just beginning. ${ }^{10,11}$

This article addresses the question of whether and under what circumstances failure to identify and disclose IFs in the clinical context could make clinicians liable for medical malpractice. Liability in this circumstance requires that the patient prove that the clinician breached his or her standard of care and that this breach caused the patient to suffer a legally compensable harm. We performed a comprehensive search of federal and state medical malpractice cases to identify all cases in which patients alleged that they had been harmed by the nondisclosure of IFs. On the basis of our analysis of the cases we identified, we conclude that health providers may face liability if they fail to disclose IFs that would have offered an opportunity to prevent or alter the course of future disease, under one of two conditions: (i) exercising the standard of care applicable to similarly situated clinicians, they fail to identify or appreciate the significance of an IF; or (ii) they fail to notify other clinicians and/or the patient of an identified IF.

\section{MATERIALS AND METHODS}

We searched all federal and state cases using the legal databases WestLaw, WestLawNext, Lexis, and Lexis Advance. We searched for all cases that included the terms "medical" or "medical malpractice" or "medical negligence" and "incidental findings" as well

${ }^{1}$ Center for Biomedical Ethics and Society, Vanderbilt University, Nashville, Tennessee, USA; ${ }^{2}$ School of Law, Vanderbilt University, Nashville, Tennessee, USA; ${ }^{3}$ Institute for Genome Sciences \& Policy, Duke University, Durham, North Carolina, USA; ${ }^{4}$ School of Law, University of Washington, Seattle, Washington, USA; ${ }^{5}$ Institute for Public Health Genetics, University of Washington, Seattle, Washington, USA; ${ }^{6}$ Department of Bioethics and Humanities, University of Washington, Seattle, Washington, USA. Correspondence: Wylie Burke (wburke@u.washington.edu) 


\section{Case} number Ref. Facts

12 Incidental finding of pancreatic cyst, present on CT scan obtained to observe liver, was not detected by radiologist; cyst was later determined to be early pancreatic cancer.

213 Incidental finding of spiculated lung nodule on CT scan, done to evaluate possible acute pulmonary embolus, was either not detected or not reported to patient; patient later found to have lung cancer.

314 Fourteen-year-old girl noted to have "incidental finding" of enlarged aorta on echocardiogram following multiple trauma; pediatric cardiologist in Hawaii did not recognize significance but recommended follow-up. Plaintiff alleged that this recommendation was not effectively communicated to receiving hospital in Texas. Child subsequently died of aortic dissection.

$4 \quad 15 \quad$ X-ray report stated in part "Noncalcified pulmonary parenchymal nodule, right mid lung.... Tumor cannot be excluded." Physician's assistant initialed report but did not inform either the patient or supervising physician; patient was diagnosed 1 year later with lung cancer.

$5 \quad 16$ Oncologist who obtained positron emission tomography scan to assess stage of Hodgkin disease failed to act on radiologist's report of incidental finding of enlarged bladder; patient later suffered renal failure due to urinary retention and neurogenic bladder.

617 Physicians failed to detect rare arteriovenous malformation on CT scan of patient presenting with history of learning difficulties and previous head trauma.
$7 \quad 18 \quad$ Neurologist seeing patient for weakness of lower extremities obtained magnetic resonance imaging that showed incidental finding of moderate hypertrophy of adenoidal soft tissue; neurologist dismissed finding as likely to be due to recent viral illness; 2 years later, the patient was diagnosed with nasopharyngeal cancer.
819 Patient who presented to ER with musculoskeletal complaints of back pain, argued that incidental finding of possible ureteral stone by radiologist was not disclosed and acted upon, resulting in additional harm.

\section{Outcome}

Radiologist admitted that she was negligent in failing to detect and report cyst on first CT scan; liability was not barred by statute of limitations.

Trial court denied attending physician's motion for summary judgment motion; the covering physician was granted summary judgment.

Defendants were denied summary judgment because of triable issues about recognition of significance of enlarged aorta or communication with receiving hospital.

\section{Supervising physician was denied summary judgment despite lack of expert testimony about duty of physician's assistant to inform him.}

Provider unsuccessfully argued that the case should not go forward on the ground that the statute of limitation had expired.

\begin{abstract}
Jury found that defendant did not breach standard of care; per expert testimony at trial, the incidental finding was considered so rare and subtle that a reasonable, prudent general radiologist would be unlikely to recognize its import in the context of the patient's presentation.
\end{abstract}

Jury found that the neurologist did not breach standard of care for neurologists.

\begin{abstract}
Summary judgment for defendants upheld; court found that lower court correctly determined that there was insufficient evidence to demonstrate a breach of the standard of care by either the ER physician or the radiologist; the court ruled that the radiologist read the film correctly but had no obligation to communicate with the patient or the ER physician.
\end{abstract}

$C T$, computed tomography; ER, emergency room.

as cases specifically involving genetics or genomics and imaging and radiology. All cases were reviewed to determine whether the claimant (patient) had asserted that he or she had been harmed as a result of nondisclosure of IFs. We identified eight relevant cases involving medical imaging but none involving any other area of medical practice, including genetics or genomics.

In our analysis, we considered the legal context for each case: after a patient files a complaint alleging that he was harmed as a result of nondisclosure of IFs, both sides engage in "discovery" to learn more about the facts of the case. At the end of that process, the defendant may request a summary judgment, arguing in essence that even if all facts were interpreted in favor of the plaintiff, the plaintiff could not prevail. For example, the facts might be insufficient to prove an essential element of negligence, or the claims might be barred on procedural grounds such as a statute of limitations. The court then rules on the defendants' arguments. Of note, if the motion is based on procedural grounds, the court will not address the patient's substantive claim. If the court grants summary judgment, the case is resolved in favor of the defendant. However, denial of summary judgment does not represent a substantive judgment about the plaintiff's case; it only means that there are sufficient disputed facts to allow the case to proceed either to trial or (frequently) to settlement, the details of which are typically private.

\section{RESULTS}

In the eight imaging cases identified in our search (Table 1), the IF was either not recognized or not acted upon. In five of 
the cases, the defendant attending physicians were faced with possible liability for the harm that befell the patient as a result of not recognizing or addressing the IF.

One case resulted in a finding of physician liability (Lo v. Burke $)^{12}$ (case 1 , Table 1 ). In that case, a radiologist reading an abdominal computed tomography (CT) scan for a suspected liver tumor failed to note a $3 \mathrm{~cm}$ cyst in the pancreas and, in fact, mistakenly reported that the pancreas was with within normal limits. A later CT scan revealed growth of the cyst, which was ultimately determined to be pancreatic cancer and resulted in the death of the patient. The plaintiffs and their expert witnesses successfully argued that had the initial scan been read correctly, the cyst could have been removed before becoming malignant.

In the remaining four cases involving possible liability (cases 2 through 5, Table 1), the defendants' failure to win on summary judgment implied that there were issues of negligence to be litigated. In Davy v. Schiffer, ${ }^{13}$ the patient's attending physician, who had allegedly failed to tell the plaintiff about a CT finding suggestive of lung cancer, was denied summary judgment. In that case, the codefendant, a covering physician, was found not to be vicariously liable for failing to know about and disclose the IF and won summary judgment in an unpublished opinion. In Durham v. County of Maui, ${ }^{14}$ a 14 -year-old girl died of aortic dissection 2 years after suffering severe trauma. Evaluation at the time of the accident included an echocardiogram, which a pediatric cardiologist read as showing an IF of an enlarged aorta. The defendants were denied summary judgment because there were unresolved issues concerning whether the cardiologist negligently failed to recognize the clinical significance of this finding and whether his recommendation for follow-up should have been effectively communicated when the girl was transferred to another hospital for care. In the case of Cooper v. Ciccarelli, ${ }^{15}$ the supervising physician was determined not to be entitled to summary judgment when his physician's assistant failed to notify either him or the patient of a reading of a chest X-ray that included an IF of a "[n]on-calcified pulmonary parenchymal nodule, right mid lung.... Tumor cannot be excluded." The patient was diagnosed with lung cancer a year later. In Workman v. O'Bryan ${ }^{16}$ an oncologist who had failed to address an IF of an enlarged bladder noted by the radiologist was sued when the patient was later diagnosed with a neurogenic bladder and renal failure. The oncologist's lawyers unsuccessfully argued on procedural grounds that the statute of limitations had expired. Defendant physicians who lost on summary judgment probably went on to settle these claims.

In one case, Stallworth v. Boren ${ }^{17}$ (case 6, Table 1), the provider was found to have acted within the standard of care given the circumstances. In this case, the patient presented with a history of a traumatic head injury, chronic headaches, and dyslexia. Several X-rays and CT scans were obtained. Seven years later, the patient suffered an intracranial hemorrhage from a rare congenital arteriovenous malformation. Experts testified that the significance of the malformation was unlikely to have been recognized by a general radiologist, and in addition that it had likely matured and become much more evident several years after the initial scans. Thus, the IF was deemed to be so rare, unusual, and inconsistent with the patient's presentation that the defendant, a general diagnostic radiologist, was found not to have breached the standard of care by failing to recognize and address the finding.

In two cases, defendants prevailed in their motions for summary judgment because the plaintiffs failed to offer pertinent expert testimony. In Riley v. Stone (case 7, Table 1), ${ }^{18}$ a patient presented to a neurologist with a complaint of lowerextremity weakness; a magnetic resonance imaging of the head was ordered to ascertain if there was a neurologic etiology to the complaint of weakness. No neurologic abnormality was found but nasopharyngeal soft tissue swelling was noted by the neurologist and diagnosed as consistent with a mild upper respiratory infection. Nearly 3 years later, the patient was diagnosed with a nasopharyngeal cancer. Despite the fact that the initial finding was later related to a malignancy, the court found that the neurologist had conformed to neurologists' standard of care in assessing the finding, given the presenting complaint of the patient, and that testimony by an otolaryngologist, to the effect that the airway finding should have been worked up further, was not pertinent. In Cifaretto v. Dalton ${ }^{19}$ (case 8, Table 1), the defendants prevailed in their motion for summary judgment against allegations that they had negligently failed to identify and follow up on an IF unrelated to the patient's presenting complaint. In that case, the patient presented to the emergency department with lower back pain following a fall. The emergency physician read a lumbar spine X-ray as revealing lumbar disc narrowing. The patient's emergent back complaint was treated, and he was referred to follow-up with his family doctor. The patient's symptoms resolved and he did not seek follow-up. A radiologist who later read the X-ray noted an IF of a calcification that "could represent a calcified lymph node although a ureteral stone cannot be clearly excluded," but this reading was not communicated to either the emergency physician or the patient's family doctor. Several months later, the patient developed a urinary tract infection and urosepsis related to the ureteral stone and subsequently sued the emergency physician. In this case, plaintiffs failed to provide evidence either that the emergency physician should have noted and acted on the calcification or that the radiologist should have communicated his observation to the emergency physician or the patient's primary-care physician.

\section{DISCUSSION}

We did not find any case law regarding IFs from genetic or genomic testing, most likely because WES/WGS and other genome-scale tests are just beginning to enter clinical practice. However, we identified eight cases involving IFs from medical imaging. Although the number of cases is small, with most of the decisions addressing motions for summary judgment, the cases fall squarely within the domain of medical malpractice law and therefore provide insights into how the courts may 
approach claims that patients were harmed when IFs were not identified, disclosed, or acted upon. Such assertions will probably become more common because technologies such as WES/ WGS are increasingly able to detect abnormalities not pertinent to the patient's primary complaint.

The discussed cases point to the centrality of the standard of care in defining potential liability, and in particular to acknowledgment that the standard of care differs for different specialties and subspecialties, a fundamental tenet of medical malpractice law. Although all physicians examine imaging studies, they do so with varying degrees of skill. Radiologists routinely examine the whole image, whereas other physicians more often focus on the patient's presenting problem. Thus, an emergency physician evaluating a patient for acute back pain may focus on the spine, consistent with the standard of care for his specialty, ${ }^{19}$ whereas a radiologist who examines an abdominal CT for possible liver tumors should not miss a $3 \mathrm{~cm}$ cyst in the pancreas. ${ }^{12}$ Of note, evidence of the governing standard of care must be provided by an expert competent to assess the standard of care relevant to the defendant's area of practice. A major issue in some of these cases was whether the plaintiffs had offered appropriate expert testimony to demonstrate that the defendant had failed to comply with the applicable standard of care. Thus in Riley v. Stone, ${ }^{18}$ testimony by an otolaryngologist was not sufficient to raise a triable question concerning whether a neurologist should be expected to recognize soft tissue in the airway as a potential sign of nasopharyngeal carcinoma. This case may well have had a different outcome had a neurologist testified that the soft tissue finding should have led to further evaluation.

If an IF was identified and its clinical significance understood, the next question was who should receive the information. In one case, the court held that a supervising orthopedic surgeon was not entitled to summary judgment when his physician's assistant failed to inform him of a chest X-ray finding of a possible tumor. ${ }^{15}$ The surgeon had testified that his staff was supposed to inform him of such findings. In other cases, questions were raised about the adequacy of communication of findings. In Durham v. County of Maui, ${ }^{14}$ plaintiffs presented sufficient expert testimony to avoid a motion for summary judgment; in Cifaretto v. Dalton, ${ }^{19}$ they did not.

In most of these cases, the defendant physician would not have had the skills to act upon the finding. An issue implicit in these cases is whether the physician would have had an obligation to refer the patient to another specialist had the IF been identified. Finally, in all of these cases, the patient would have experienced clear medical benefit or at least a better chance of survival had the IF been acted upon in a timely fashion, a claim essential to proceeding successfully with claims in medical malpractice. These issues have generated consensus efforts to define standards of practice in medical imaging. ${ }^{20}$

\section{Implications for genomics}

WGS/WES technologies will generate a tremendous amount of data, but whether they will reveal IFs sufficient to give rise to legal liability is a more complicated question. Unlike imaging studies, for which virtually all clinicians have some training in interpretation, almost no clinician is capable of interpreting the comprehensive results of WGS and WES. Even most geneticists are not capable of doing so. As a result, for the overwhelming majority of clinicians, data from WES/WGS will be only as accessible or useful as the tools available to interpret them. In the area of pharmacogenetics, e.g., clinicians may be told which genetic variant their patient has but will also need guidance on the changes that should therefore be made in the patient's medications. ${ }^{21}$

Therefore, for most clinicians, the standard of care will be defined almost entirely by the results and interpretations that are "pushed" to them by the laboratory. Preliminary data suggest that clinicians would prefer a targeted analysis that limits IFs, although patients may favor greater access to IFs. ${ }^{22}$ Standard of care for these clinicians will rest on the clinician's discretion about how to respond to the results provided to them by the laboratory, including when they should refer. For the small subset of clinicians, predominantly medical geneticists, who will routinely examine genomic results directly when WES/WGS is ordered, a separate standard of care will emerge, likely comparable with that defined for laboratory geneticists.

The most pertinent standard of care, therefore, will be that governing genomics laboratory medicine specialists and the institutions in which they work. Both will play a major role in deciding which results to return and what decision support accompanies the results. Given the growing emphasis on ensuring greater access by clinicians to patient information and decision support, driven in part by health-care reform, the development of electronic medical records, and patient interest, it is likely that laboratories and health-care systems will face increased liability for failure to develop effective tools to communicate IFs deemed clinically actionable.

There has been debate among the genetics community about what types of results should be returned, ${ }^{10,11}$ incorporating discussion about how to define the clinical utility and actionability of genomic results and what weight those factors ought to receive, the likelihood that clinical utility will change over time for many results, and the significance of personal utility for genomic data that lack clear clinical value. The case law reviewed here suggests that the determinative factor for liability will be the potential for a result to inform medical interventions aimed at improving the health outcome of the person tested. Consensus guidelines to define results that meet these criteria will be helpful. Notably, however, compliance with guidelines may not always immunize providers from tort liability, especially where guidelines conflict.

Therefore, when incidental information arising from genomic testing reveals a significant health risk for which an effective preventive or therapeutic intervention is available, the law may well require its disclosure by the laboratory to the provider, who then must inform the patient. Disclosure would include a description of the disorder and its known course, validity of the information, and available interventions or recommendations for preventive treatment. The provider's duty may exist 
regardless of whether the provider realized and disclosed the potential for acquiring the incidental information before undertaking genomic testing, because even without prior disclosure of this possibility, there would be a duty to act on the information if failure to act would result in harm to the patient. Large health-care institutions, in which laboratory results are reported to a variety of clinicians, may choose to set up a system designating which provider is the most appropriate communicator in order to ensure that patients are informed.

Yet not all failures to recognize or disclose IFs are likely to give rise to liability. For some results, opinions about clinical utility may vary sufficiently to make the standard of care difficult to define. If an IF indicates a moderate increase in cancer risk, e.g., some people might view it as sufficiently predictive to alter cancer screening recommendations whereas others might not. But withholding of information that is ambiguous or of no clinical utility would be unlikely to give rise to a viable negligence suit, unless the information would ordinarily trigger further medical follow-up. In any case alleging negligent failure to identify, disclose, or act upon an IF, the patient would have to demonstrate that the information was or should have been delivered to the clinician by the laboratory, establish the materiality of the information, and demonstrate that she/he had suffered legally compensable harm with ascertainable, quantifiable damages from not getting the information.

IFs from WES/WGS pose an additional question that does not arise in medical imaging: whether or not the clinician is obligated to return IFs that have implications for reproductive risk, such as carrier status for autosomal recessive disorders. The failure to do so could potentially lead to a wrongful birth or wrongful life suit, if the person tested subsequently had a child with an inherited disorder for which carrier detection was possible. Many states, however, forbid such suits as a matter of case law or statute. As a result, the resolution of this issue may vary in different jurisdictions and may be influenced by evolving standards of laboratory practice regarding which results to return.

\section{Anticipated changes in clinical utility over time}

With rapid evolution of knowledge in genomics, we can anticipate the additional problem that many IFs from genomic testing may gain clinical relevance years after testing is completed, and some may lose significance as more is learned. This reality raises additional questions about the obligations of health providers and health-care systems. Will health systems have a responsibility to store and update test results? Will providers be expected to notify patients of updated information?

Under the current view, a health provider's duty to a patient concludes after resolution of an episode of illness, with transfer of care to another provider, or if the patient fails to seek care for an extended period of time. ${ }^{23}$ Patients are increasingly unlikely to have a single longitudinal relationship with a particular physician. Rather, they often have a cascade of providers, including specialists, alternative and complementary medicine providers, hospitalists, and urgent care "drop-in" clinic providers, instead of, or in addition to a primary-care physician..$^{24,25}$ In this context, any duty to recontact a patient with new clinical information is unlikely to extend perpetually or to require more than reasonable efforts. ${ }^{26}$ Cases in which a duty to recontact about new findings has been found have uniformly involved side effects of medical interventions delivered to patients, such as radiation and diethylstilbestrol, ${ }^{27,28}$ not incidental information arising from diagnostic and screening tests. Whether courts will extend these cases to create a duty to warn about new interpretations of previously performed tests is unclear. ${ }^{29,30}$

In addition, patients are increasingly likely to have a consumer-oriented approach to their health care. ${ }^{31}$ Because of greater access to health information and the reframing of health care as a commodity, patients may behave in an autonomous fashion, acquiring more information on their own and granting less deference to the physician. ${ }^{22,31}$ As health systems grapple with the evolution of genomic knowledge, patients who have had genome-scale testing may be encouraged to seek regular updates as the most efficient method of informing them of updated information, although whether such acts will ever vitiate clinicians' legal responsibilities is by no means clear.

\section{Conclusion}

Whole-genome and whole-exome testing strategies are beginning to enter clinical practice. They offer opportunities for efficiency and cost reduction but raise difficult questions about a provider's duty to return IFs. No case law yet exists for this area of practice, but comparable questions concerning IFs are raised by high-resolution imaging studies. We identified eight relevant imaging cases. We conclude that if a genomic laboratory specialist identified and reported an IF, the receiving provider would likely be expected to reveal it to the patient and refer as necessary if the results could be used to improve medical outcomes. Failure to do so arguably would be a breach of the standard of care, if not now, in the near future. Practice standards for genomics laboratory specialists are likely to emphasize the importance of reporting IFs that have implications for medical care to improve outcomes, with appropriate guidance regarding their clinical implications. There is unlikely to be a duty for either the laboratory specialist or the ordering physician to disclose findings that are ambiguous or have unknown clinical utility, unless they represent uncertainties that would typically be subject to further medical work-up. However, some results may pose difficulties in determining the threshold for disclosure, and the obligation to return findings related to reproductive risk is unclear.

With respect to genomic information that evolves over time, the standard of care is vague, especially when mapped against the contemporary doctor-patient relationship. It seems unlikely that liability would accrue for information that was not known or knowable during the tenure of the doctor-patient relationship. Once the relationship has ceased, the duty is generally concluded. With greater mobility and a volatile medical marketplace, such relationships are considerably more transitory than in decades past. Over time, biomedical health informatics may provide new solutions for the updating of genomic test 
information. If so, the respective responsibilities of health-care systems, providers, and patients to access updated test results will be an important issue to resolve.

\section{ACKNOWLEDGMENTS}

This work was supported in part by the following grants from the National Institutes of Health: R01-GM081416-01A1 (to S.H.). 1R21HG00612-01 (to E.W.C.), and the Vanderbilt site of the electronic Medical Records and Genomics (eMERGE) Network, U01-HG HG006378 (to Dan M. Roden).

\section{DISCLOSURE}

The authors declare no conflict of interest.

\section{REFERENCES}

1. IOM (Institute of Medicine). Integrating Large-Scale Genomic Information into Clinical Practice: Workshop Summary. National Academies Press: Washington, DC, 2012.

2. Bamshad MJ, Ng SB, Bigham AW, et al. Exome sequencing as a tool for Mendelian disease gene discovery. Nat Rev Genet 2011;12:745-755.

3. Kohane IS, Hsing M, Kong SW. Taxonomizing, sizing, and overcoming the incidentalome. Genet Med 2012;14:399-404.

4. Solomon BD, Hadley DW, Pineda-Alvarez DE, et al. Incidental medical information in whole-exome sequencing. Pediatrics 2012;129:e1605-e1611.

5. Clayton EW, Ross LF. Implications of disclosing individual results of clinical research. JAMA 2006;295:37; author reply 37; author reply 38.

6. Clayton EW, McGuire AL. The legal risks of returning results of genomics research. Genet Med 2012;14:473-477.

7. Fabsitz RR, McGuire A, Sharp RR, et al. (National Heart, Lung, and Blood Institute working group). Ethical and practical guidelines for reporting genetic research results to study participants: updated guidelines from a National Heart, Lung, and Blood Institute working group. Circ Cardiovasc Genet 2010;3:574-580.

8. Miller FA, Christensen R, Giacomini M, Robert JS. Duty to disclose what? Querying the putative obligation to return research results to participants. J Med Ethics 2008;34:210-213.

9. Wolf SM, Lawrenz FP, Nelson CA, et al. Managing incidental findings in human subjects research: analysis and recommendations. J Law Med Ethics 2008 Summer;36:219-248, 211.
10. Berg JS, Khoury MJ, Evans JP. Deploying whole genome sequencing in clinical practice and public health: meeting the challenge one bin at a time. Genet Med 2011;13:499-504.

11. Green RC, Berg JS, Berry GT, et al. Exploring concordance and discordance for return of incidental findings from clinical sequencing. Genet Med 2012:14:405410.

12. Lo v. Burke, 455 S.E. 2 d 9 (Va. 1995).

13. Davy v. Schiffer, 6/6/2008 NYL 30 (col 1), 2008 NY Misc. LEXIS 9327.

14. Durham v. County of Maui, 2010 WL 2943358 (D. Haw. 2010).

15. Cooper v. Ciccarelli, 2009 WL 539911 (D. Kan. 2009).

16. Workman v. O'Bryan, 2001 WL 663819 (Ind. App. 2001).

17. Stallworth v. Boren, 54 P.3d 923 (Haw. App. 2002).

18. Riley v. Stone, 900 A.2d 1087 (R.I. 2006).

19. Cifaretto v. Dalton, 2011 WL 831867 (N.J. Super. App. Div. 2011).

20. Berland LL, Silverman SG, Gore RM, et al. Managing incidental findings on abdominal CT: white paper of the ACR incidental findings committee. J Am Coll Radiol 2010;7:754-773.

21. Pulley JM, Denny JC, Peterson JF, et al. Operational implementation of prospective genotyping for personalized medicine: the design of the Vanderbilt PREDICT project. Clin Pharmacol Ther 2012;92:87-95.

22. Townsend A, Adam S, Birch PH, Lohn Z, Rousseau F, Friedman JM. "I want to know what's in Pandora's Box": comparing stakeholder perspectives on incidental findings in clinical whole genomic sequencing. Am J Med Genet $A$ 2012;158A:2519-2525

23. Doyle v. Planned Parenthood, 31 Wash. App. 951 (1980)

24. Moore G, Showstack J. Primary care medicine in crisis: toward reconstruction and renewal. Ann Intern Med 2003;138:244-247.

25. Solet DJ, Norvell JM, Rutan GH, Frankel RM. Lost in translation: challenges and opportunities in physician-to-physician communication during patient handoffs. Acad Med 2005;80:1094-1099.

26. Tresemer v. Barke, 86 Cal.App 3d 617 (1978).

27. Blaz v. Michael Reese Hosp. Fdn., 74 F. Supp. 2 d 803 (N.D. III. 1999).

28. Mink v. University of Chicago, 460 F. Supp. 713 (N.D. III. 1978)

29. Rothstein MA, Siegal $G$, Health information technology and physicians' duty to notify patients of new medical developments. Houston I Health Law Policy 2013, in press. http://ssrn.com/abstract=2126126.

30. Rothstein MA. Currents in contemporary bioethics: physicians' duty to inform patients of new medical discoveries: the effect of health information technology. J Law Med Ethics 2011;39:690-693.

31. Buetow $S$, Jutel $A$, Hoare K. Shrinking social space in the doctor-modern patient relationship: a review of forces for, and implications of, homologisation. Patient Educ Couns 2009;74:97-103. 